Yu. V. Gurchin ${ }^{1, *}$, V. A. Krasnov ${ }^{1}$, V.P. Ladygin ${ }^{1}$, Yu. S. Anisimov ${ }^{1}$, A. Yu. Isupov ${ }^{1}$, M. Janek ${ }^{1,3}$, J.-T. Karachuk ${ }^{1,4}$, A. N. Khrenov ${ }^{1}$, A. S. Kiselev ${ }^{1}$, V. A. Kizka ${ }^{1}$, J. Kliman ${ }^{2,5}$, A. N. Livanov ${ }^{1}$,

A. I. Malakhov ${ }^{1}$, V. Matousek ${ }^{2}$, M. Morhac ${ }^{2}$, S. G. Reznikov ${ }^{1}$, I. Turzo ${ }^{2}$, T. A. Vasiliev ${ }^{1}$

\title{
TARGET POSITION MONITOR FOR INTERNAL TARGET STATION AT THE NUCLOTRON
}

\section{Submitted to «Particles and Nuclei, Letters»}

\footnotetext{
${ }^{1}$ Veksler and Baldin Laboratory of High Energies, JINR, Dubna, Russia

2 Institute of Physics, Slovak Academy of Sciences, Bratislava, Slovakia

${ }^{3}$ P. J. Šafarik University, Košice, Slovakia

${ }^{4}$ Advanced Research Institute for Electrical Engineering, Bucharest, Romania

${ }^{5}$ Flerov Laboratory of Nuclear Reactions, JINR, Dubna, Russia

* E-mail: gurchin@sunhe.jinr.ru
} 
Гурчин Ю. В. и др.

E13-2006-95

Датчик положения мишени для станции внутренней мишени нуклотрона

Описан принцип работы датчика положения внутренней мишени нуклотрона. Датчик был разработан для использования в экспериментах с детектированием частиц при рассеянии вперед. Представлены первые результаты, полученные с использованием датчика положения мишени на пучке поляризованных дейтронов нуклотрона.

Работа выполнена в Лаборатории высоких энергий им.В.И.Векслера и А. М. Балдина ОИЯИ.

Препринт Объединенного института ядерных исследований. Дубна, 2006

Gurchin Yu. V. et al.

E13-2006-95

Target Position Monitor for Internal Target Station at the Nuclotron

The principle of the internal target position monitor at the Nuclotron is described. It has been developed for the use in experiments with the detection of the particles in the forward direction. The first results obtained using the target position monitor with polarized deuteron beam at the Nuclotron are presented.

The investigation has been performed at the Veksler and Baldin Laboratory of High Energies, JINR. 


\section{INTRODUCTION}

The main purpose of LNS (Light Nuclei Structure) project is the broadening of the energy and angular ranges in the measurement of different observables in the processes including three-nucleon systems $[1,2]$. In moderate energy range Faddeev's technique is still correct, and comparison of the experimental results and the theory can be done with high precision.

The main aim of this experimental program is the obtaining of the information on the spin-dependent part of three-nucleon forces from two processes: $d p$-elastic scattering and $d p$-breakup reaction with the detection of two nucleons at the energies $300-500 \mathrm{MeV}[1,2]$.

On the other hand, the spin physics program proposed at VBLHE and RIBF (Japan) requires efficient polarimetry of the deuteron beam at high energies. Therefore, a new high-energy deuteron beam polarimeter based on the measurements of the asymmetry in $d p$-elastic scattering has been proposed at Internal Target Station (ITS) at the Nuclotron [3]. This polarimeter should work in the energy range of 300-2000 MeV.

The ITS setup is well suited for the study of energy dependence of polarization observables for the $d p$-elastic scattering. At cyclotron facilities, measurement of energy dependence is very expensive because the change of beam energy in accelerator takes much time (typically more than one day). The Nuclotron can accelerate a polarized deuteron beam from several tens of $\mathrm{MeV}$ to higher than $1 \mathrm{GeV}$ and can provide a good opportunity to measure the energy dependence.

The detection of $d p$-elastic scattering at ITS is realized by the coincidence of the signals from scintillation counters with the finite size. Therefore, it is necessary to know the interaction point for good resolution on the angle. On the other hand, the knowledge of interaction point position is necessary to avoid the errors in the polarization observables caused by the false asymmetry. To satisfy these requirements the internal target position monitor at the Nuclotron has been developed.

\section{INTERNAL TARGET POSITION MONITOR}

The experiments on the $d p$-elastic scattering investigation are realized using new version of Internal Target Station of the Nuclotron [4]. The target is the disk with the slits which are located on the axle of stepper motor. The active material 
of the targets $\left(\mathrm{CH}_{2}, \mathrm{C}, \mathrm{Al}, \mathrm{Cu}\right.$, etc. $)$ is put in disk-slits. There is a target position sensor at the bottom of the target disk. The whole construction is disposed in the vacuum sphere. This sphere is fixed on the flanges of the Nuclotron ion tube. The disk has to be turned with empty slit to the center of the ion tube during the time the particles are accelerated. When the particles have the required energy, the disk moves the selected target toward the beam. The scheme of new version of Internal Target Station is shown in Fig. 1.

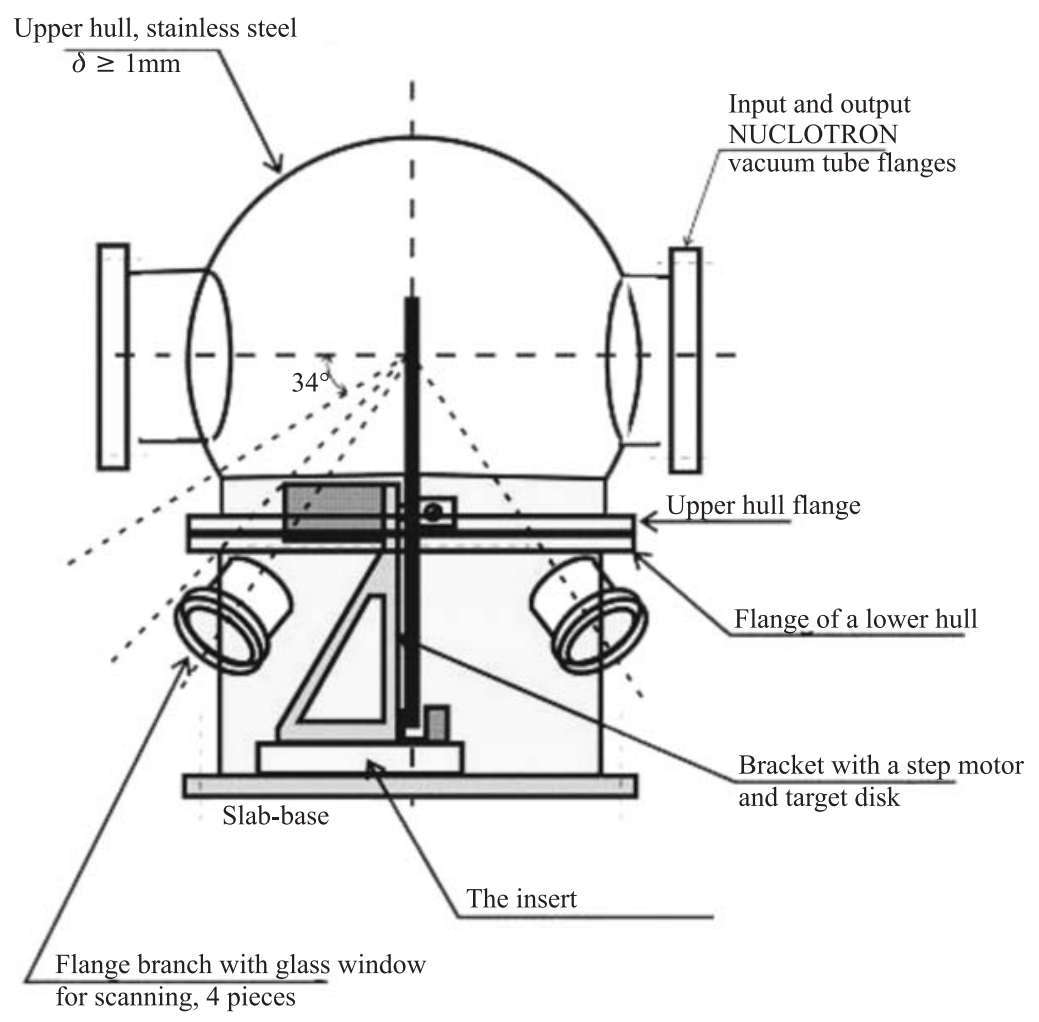

Fig. 1. Scheme of the Internal Target Station

The principle of the functionality of the internal target station is schematically outlined in Fig. 2 and described in detail in [5, 6]. From the point of view of the experiment one needs to know, as precisely as possible, the position of the target during its motion across the ion tube. For this reason the target station control equipment was supplemented with a target position monitor. It consists of the registration of the input pulses of the stepper motor. The stepper motor moves the target along the desired trajectory during each accelerator cycle. At the beginning the target is set to its initial position, which is indicated by aperture 


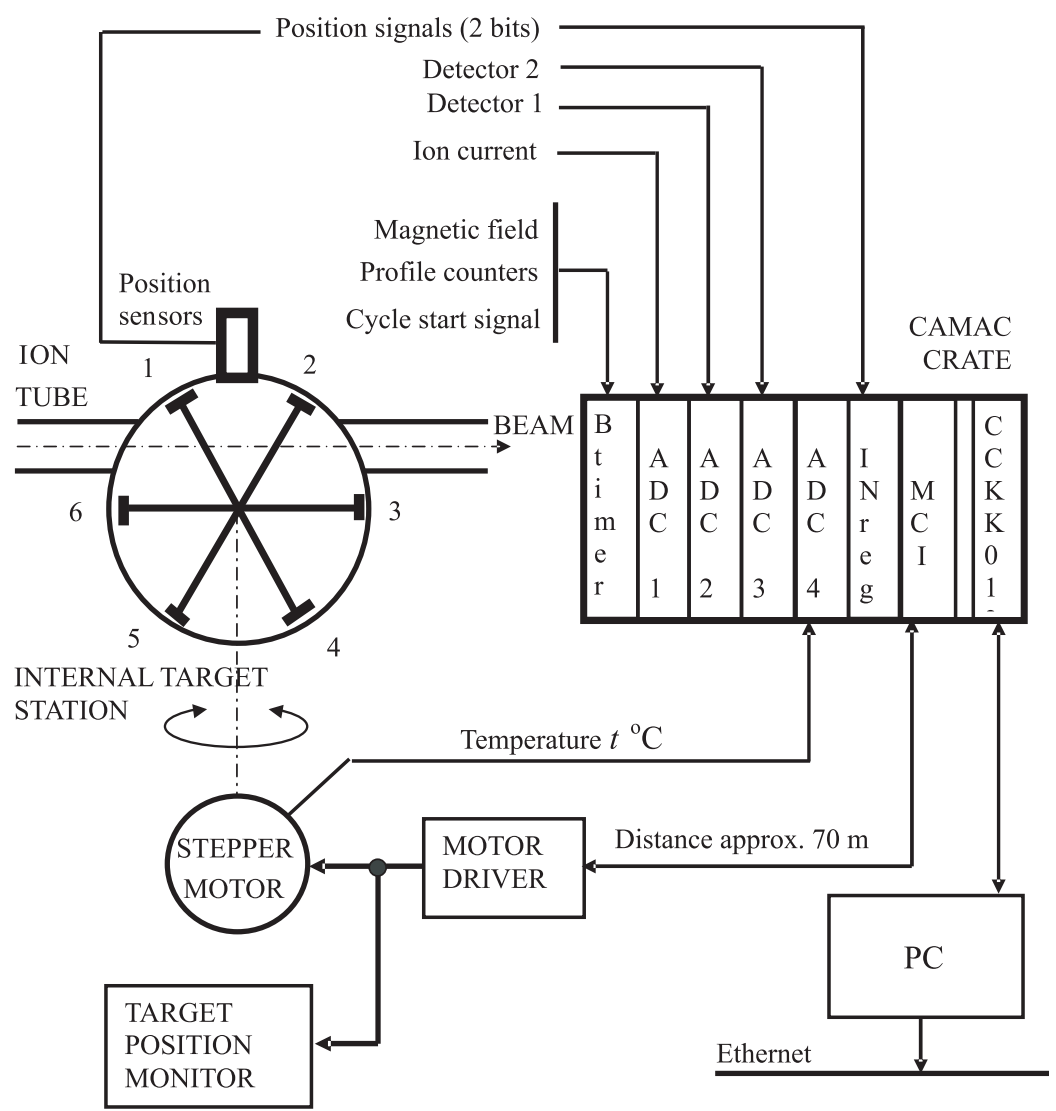

Fig. 2. Block scheme of the internal target station control and target position monitor

and the position sensor working in infrared region. To turn the stepper motor by 360 degrees one needs 12800 pulses, which for radius of target trajectory through the center of the ion tube, $R=112 \mathrm{~mm}$, corresponds to the precision of $0.05 \mathrm{~mm} /$ pulse. The synchronization of the target position registration is realized by the external detectors according to the needs of a particular experiment.

\section{DETECTION SYSTEM}

The schematic view of the detection equipment for the experiments on $d p$-elastic scattering is shown in Fig. 3 [7]. Four pairs of proton $(P)$ and deuteron $(D)$ detectors are placed in the horizontal and vertical planes symmetrically in the 


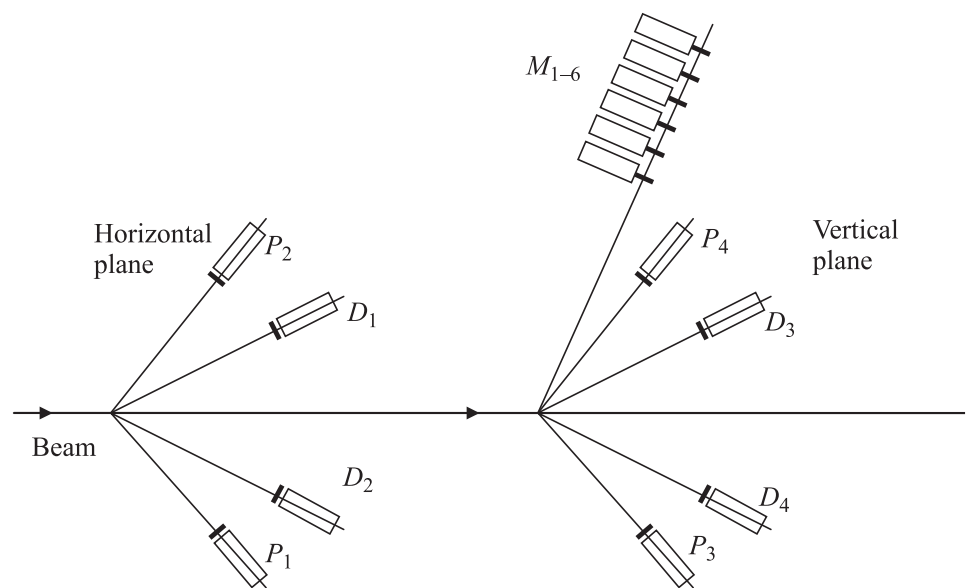

Fig. 3. Scheme of the detectors. $P$ and $D$ are the scintillation counters for the detection of the proton and deuterons, respectively, $M_{1-6}$ are the monitor scintillation counters

directions of the azimuthal angles on the left, right, up, and down. The symmetry axis of the detection system is defined by the axis of the accelerator ion-tube. Each $P$ and $D$ detector consists of 2 scintillation counters. The plastic scintillators with the thicknesses of $5 \mathrm{~mm}$ and $20 \mathrm{~mm}$ are coupled to FEU-85 photomultiplier tubes (PMT). The high voltage for PMTs is provided by distributed multichannel high voltage system [8]. Each PMTs is coupled to the high voltage cell connected by the flat cable with the system module SM-512 controlled by the computer.

The coincidences of the signals from 2 counters with the thin $(5 \mathrm{~mm})$ and thick $(20 \mathrm{~mm})$ plastic scintillators allow one to completely eliminate the accidental events. The trigger signal is therefore the sum of four-fold coincidences. The $d p$-elastic scattering events are clearly distinguished by their energy losses in the thick plastic scintillators and the differences between their time of flight from the target.

The relative intensity monitoring is realized by the detection of the charged particles in the vertical plane with the aid of six scintillation counters $M_{1-6}$.

The information about the energy losses in the plastic scintillators, time-offlight information, number of pulses from the stepper motor, time of the trigger appearance is stored for each event. The monitor counts as well as signal about the type of the spin mode of ion source was stored for each beam spill [9].

Only the information from the detectors located in the horizontal plane was used for the study of the target position monitor performance. The signals from $D$ detectors placed on the left and right were used as the trigger. 


\section{TARGET POSITION MONITOR PERFORMANCE}

The studies of the target position monitor performance have been performed using polarized deuteron beam with energy $270 \mathrm{MeV}$.

The distribution of the interaction point in $\mathrm{mm}$ for the left $(L)$ and for the right $(R)$ scattered events for the typical trajectory of the internal target is shown in Fig. 4. The figure corresponds to the case when the target moves in the direction

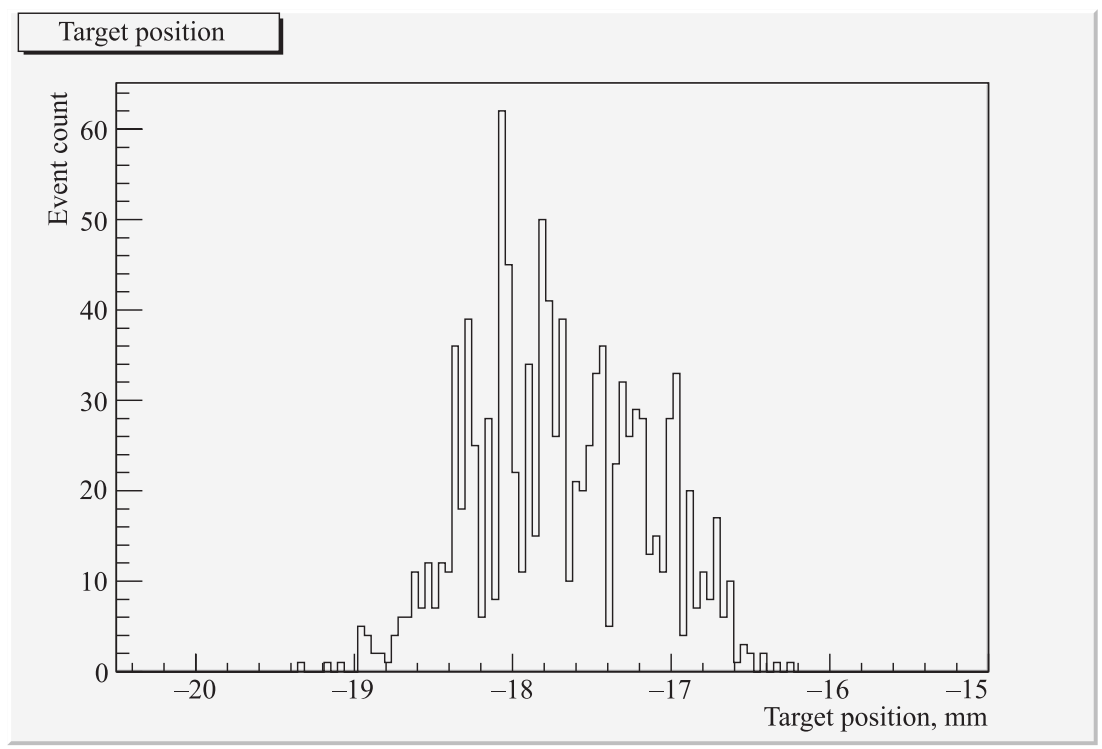

Fig. 4. Target position during the interaction in $\mathrm{mm}$

from the accelerator ring center. One can see that the size of the interaction zone is $\pm 1 \mathrm{~mm}$. The size of this zone depends not only on the beam size in the accelerator ring, but also on the trajectory of the target.

The distribution of the time of the event storage from the beginning of the acceleration in ms is shown in Fig. 5. The interactions appear between 1000 and $2000 \mathrm{~ms}$ from the beginning of the acceleration. Therefore, the current trajectory of the target allows us to use the full intensity of the beam within $\sim 1 \mathrm{~s}$.

The correlation of the time and target position is shown in Fig. 6. The observed clean correlation between the target position and time of the event storage demonstrates the proper work of the target. At the beginning of the cycle the target position has more negative values, then it changes to less negative values as it is expected for the case of target moving in the direction from the accelerator ring center. 


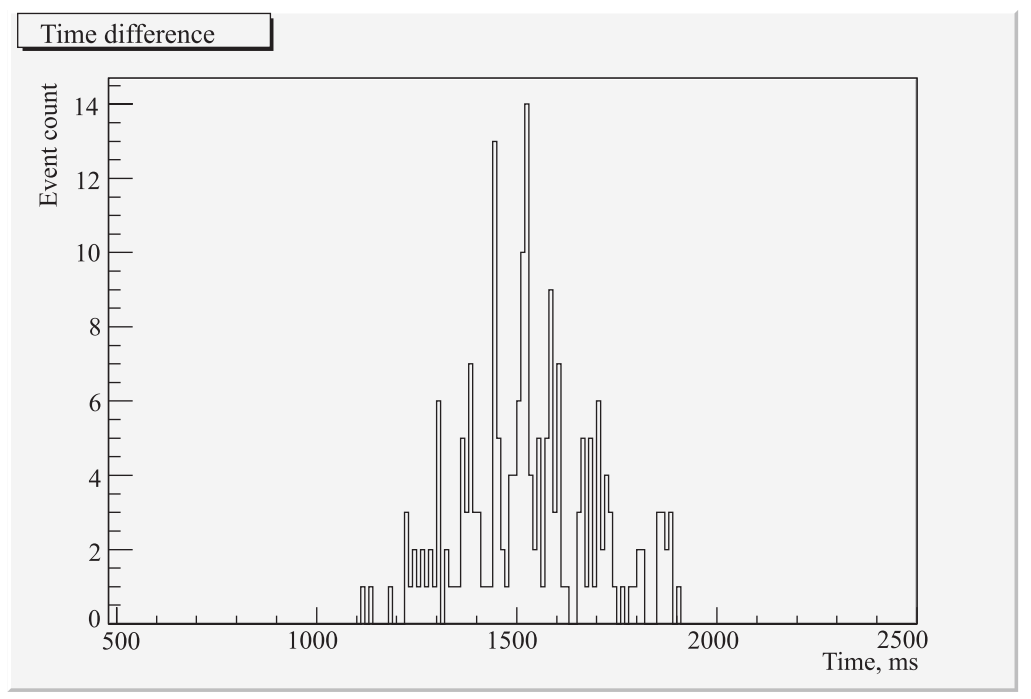

Fig. 5. Time of the event storage from the beginning of the acceleration in $\mathrm{ms}$

\section{Time difference : Target position}

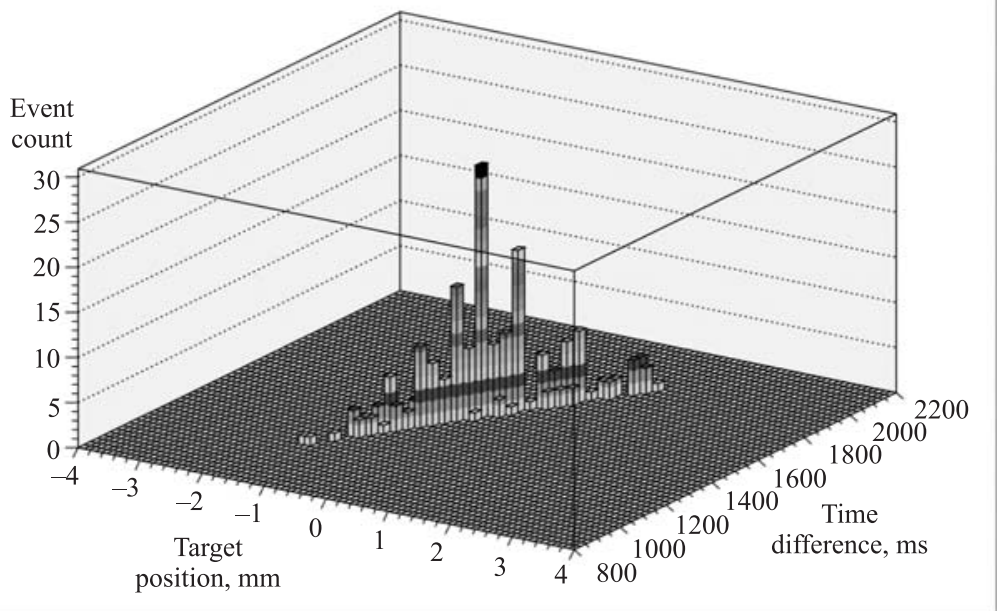

Fig. 6. Correlation of the target position and time of the event appearance for the case of target moving in the direction from the accelerator ring center

The position of the beam with the given energy inside the ion-tube can be changed in the horizontal plane by the changing of the accelerator radiofrequency. 


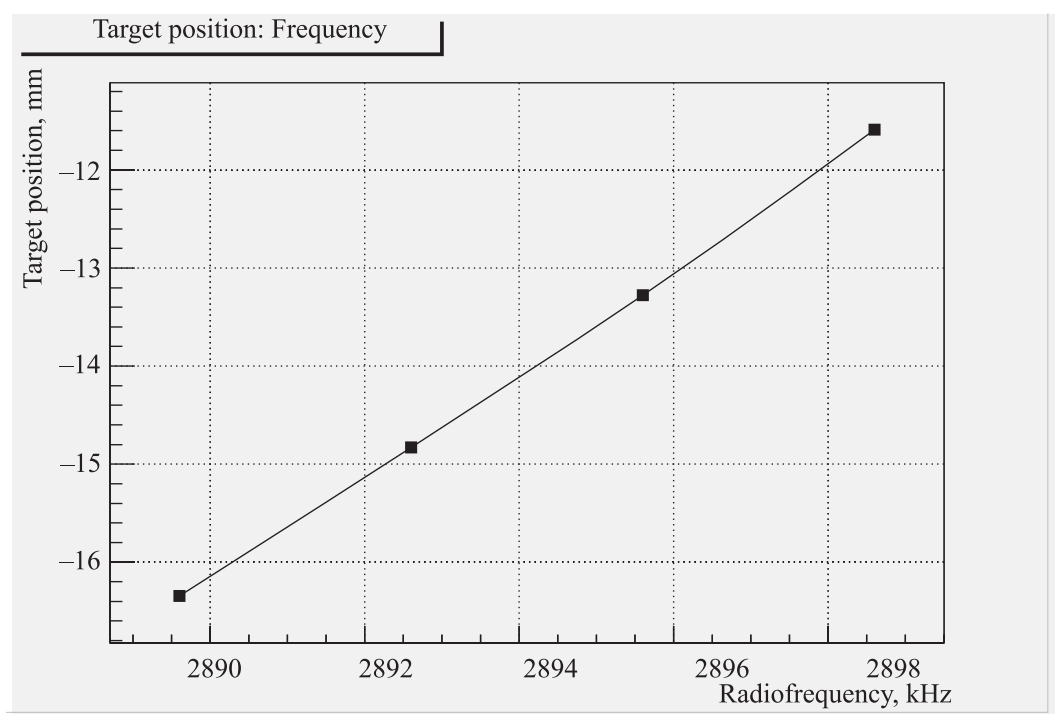

Fig. 7. Target position versus radiofrequency

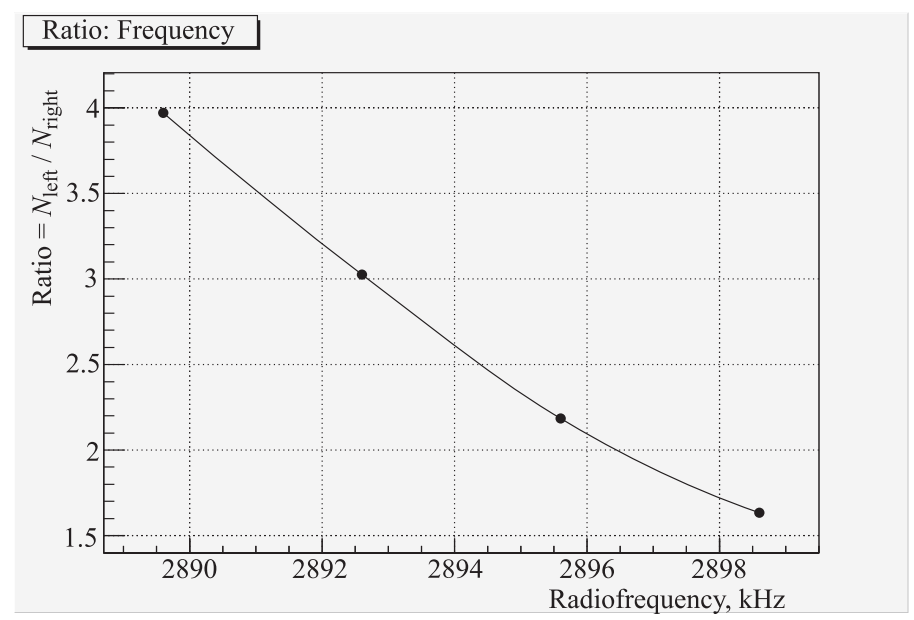

Fig. 8. Ratio from the left to right monitors versus radiofrequency

The dependence of the interaction point position for the case of the target moving in the direction from the accelerator ring center on the radiofrequency is shown in Fig. 7. One can see the changing of the interaction point position towards the 
center of the ion-tube center as the accelerator radiofrequency increases. The line in Fig. 7 is the linear approximation.

Figure 8 demonstrates the dependence of the $L / R$ monitors ratio versus the accelerator radiofrequency. The target position in the center of the accelerator ion-tube center corresponds to the value of this ratio equal 1 . The $L / R$ monitors ratio decreases as the radiofrequency increases. The dependence of the $L / R$ monitors ratio versus the position of the target is shown in Fig. 9. The $L / R$ monitors ratio is approximately 4 at the averaged position of target of $\sim-16 \mathrm{~mm}$. The $L / R$ ratio decreases, when the interaction point is more close to the center of the accelerator ion-tube

The observed peculiarities in the behavior of the target position and the $L / R$ monitors ratio confirm the correct functioning of the internal target position monitor.

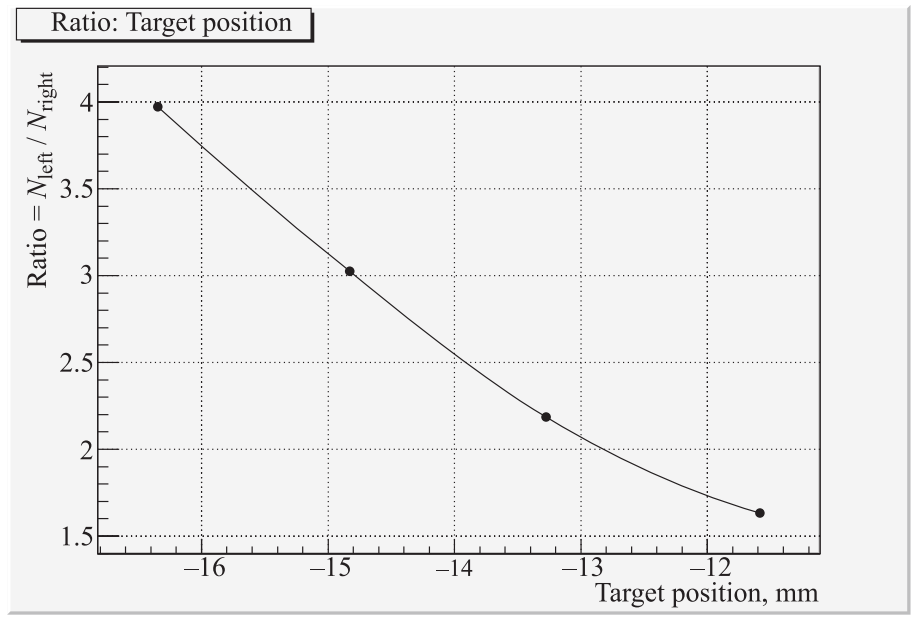

Fig. 9. Monitors ratio versus the target position

\section{CONCLUSIONS}

The results of this work can be summarized as follows.

- The internal target position monitor at the Nuclotron based on the use of the pulses from the stepper motor has been developed and tested.

- The use of the target position monitor is very powerful to select the required for the experiment trajectory of the internal target $[5,6]$.

- The precision of the interaction point can be reached is $\pm 1 \mathrm{~mm}$ for the case of the full luminosity use. 
- The interaction point can be determined for each event, that gives the opportunity to make the necessary corrections during data analysis. This is especially important for the polarization measurements to avoid the effects of the instrumental false asymmetry.

Acknowlegments. The authors are grateful to T. Uesaka and K. Suda for arising of the interest to develop the target position monitor at the Nuclotron. This work has been supported in part by the Russian Foundation for Basic Research under grants No. 04-02-17107a, No. 05-02-17743a and No. 06-02-16728a.

\section{REFERENCES}

1. Ladygin V. P. // Proc. of the XV Int. Seminar on High Energy Physics Problems, 2529 September 2000, Dubna, Russia / Eds. A. M. Baldin, V. V. Burov, A. I. Malakhov. Dubna: JINR, 2001. V.2. P. 301.

2. Ladygin V. P. et al. // Proc. of the Int. Workshop «Relativistic Nuclear Physics: from Hundreds of $\mathrm{MeV}$ to $\mathrm{TeV}$ », 10-16 September, 2001, Varna, Bulgaria. Dubna: JINR, 2001. V.1. P. 131.

3. Uesaka T., Ladygin V. P. et al. JINR Preprint E1-2005-64. Dubna, 2005; Part. Nucl., Lett. 2006. V.3[114]. P. 58.

4. Anisimov Yu.S. et al. // Proc. of the 7th Intern. Workshop on Relativistic Nuclear Physics, 25-30 August, 2003, Stara Lesna, Slovak Republic. P. 117.

5. Artiomov A. S. et al. // JINR Rapid Commun. 1996. No. 1[75]-96. P. 95.

6. Malakhov A. I. et al. // Nucl. Instr. Meth. Phys. Res. A. 2000. V.440. P. 320.

7. Khrenov A.N. et al. // Proc. of the 7th Intern. Workshop on Relativistic Nuclear Physics, 25-30 August, 2003, Stara Lesna, Slovak Republic. P. 236.

8. Astakhov V.I. http://www.hvsys.dubna.ru

9. Isupov A. Yu. // Proc. of the Advanced Studies Institute «Symmetries and SPIN» Conf. (SPIN-Praha-2005), 27 July - 3 August, Prague, Czech Republic (to be published in «Czech Journal of Physics Suppl».).

Received on June 28, 2006. 


\section{Корректор T. Е. Попеко}

Подписано в печать 12.10.2006.

Формат $60 \times 90 / 16$. Бумага офсетная. Печать офсетная.

Усл. печ. л. 0,93. Уч.-изд. л. 1,35. Тираж 325 экз. Заказ № 55508.

Издательский отдел Объединенного института ядерных исследований 141980, г. Дубна, Московская обл., ул. Жолио-Кюри, 6.

E-mail: publish@pds.jinr.ru www.jinr.ru/publish/ 